DOI: https://doi.org/10.35560/jcofarts94/203-220

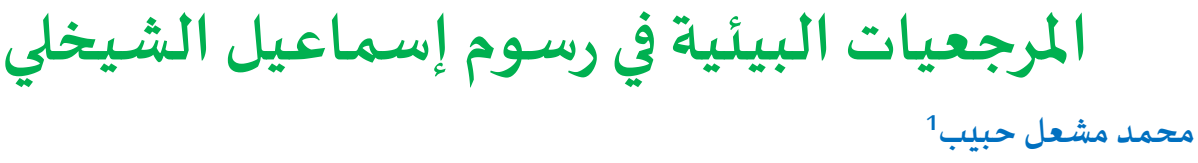

ISSN(Online) 2523-2029, ISSN(Print) 1819-5229

مجلة الأكاديمي-العدد 94-السنة 2019

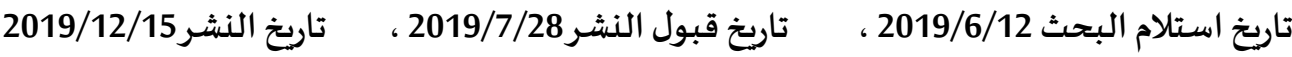
(c) (1)

This work is licensed under a Creative Commons Attribution 4.0 International License

ملخص البـحث

تعتبر المرجعيات البيئية والمتمثلة بالضيواغط الفكرية والاجتماعية والاقتصادية والسياسية والدينية

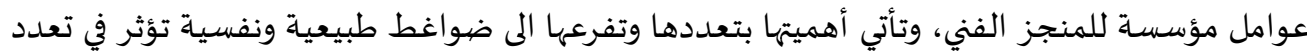

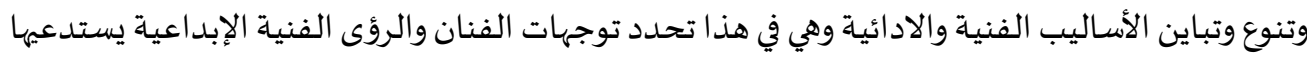
عن طريق الرموز والاشارات الدلالية على السطح البصري، ذلك لان الفكر المجتمعي يحتل في الفن عامة

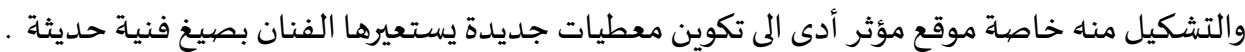
يعنى هذا البحث في دراسـة المرجعيات البيئة في رسوم الفنان إسـماعيل الشيخلي ذلك لان الخزين الفكري الهائل في ذهن الفنان العراقي بصورة عامة يتمظهر بصيورة ذهنية تتمثل بالعوامل الاجتماعية والفكرية

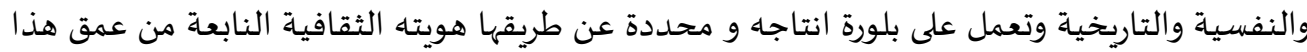

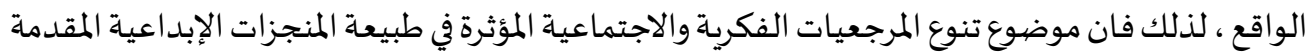

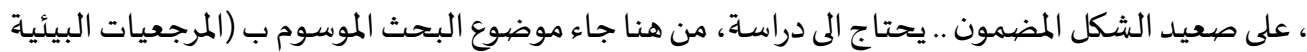
في رسوم إسماعيل الشيخلي).

(الكلمات المفتاحية : المرجعيات ، البيئية ، إسماعيل الشيخلي) المقدمة

منذ ان وعى الانسان ان رسوم الحيوانات في الكهوف تجعله يسيطر عليها بدأ مفهوم البيئة وعلاقتها بالإنسـان

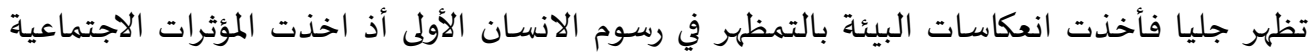

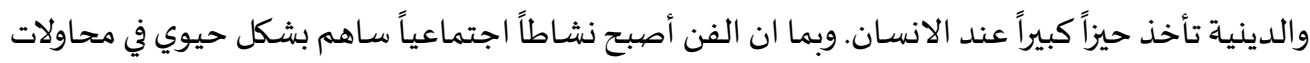

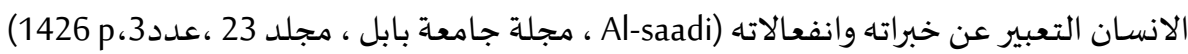
أذ استطاع الفنان ان يجسد انطباعاته الفكرية عن البيئة وما يحيط به . وسرعان ما اخذت هذه النظم

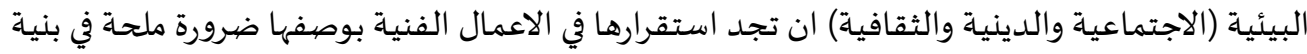

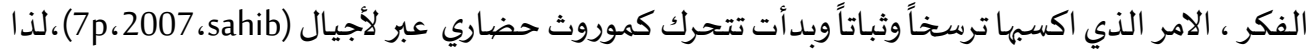

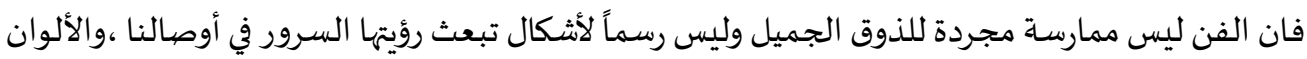




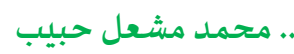
المرجعيات البيئية في رسوم إسماعيل الشيخلي.

مجلة الأكادييي-العدد 94-السنة 2019

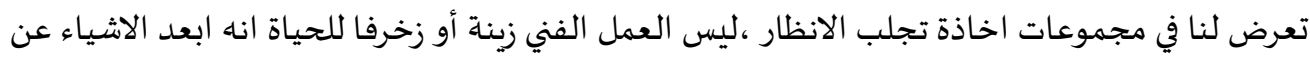

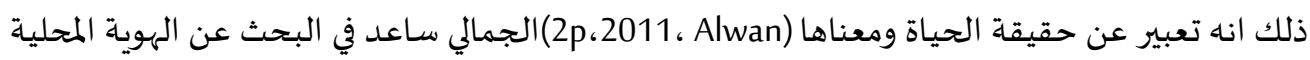

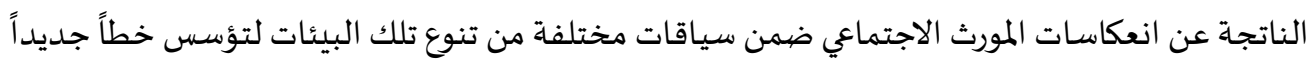

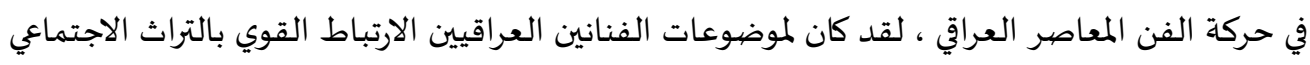

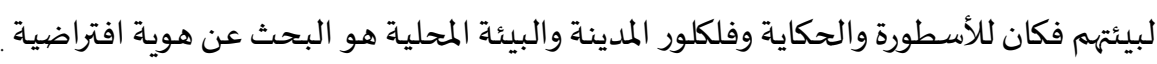

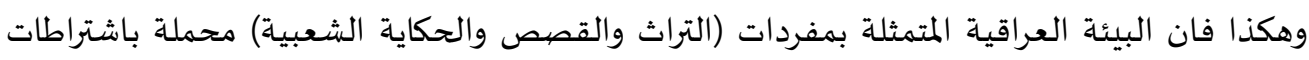

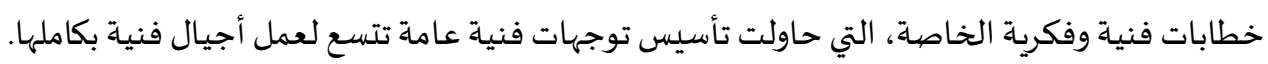

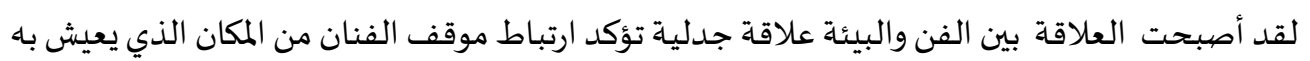

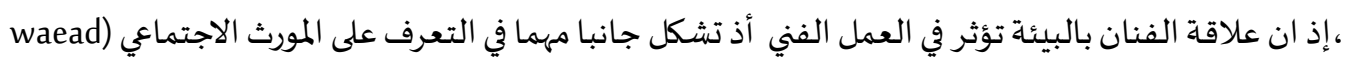

. 3p،2017،

ان الفنان العراقي المعاصر لم يغادر مرجعياته المحلية و جذوره أذ تتميز تلك المفردات البيئية في الحكاية

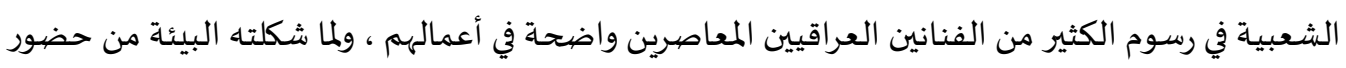

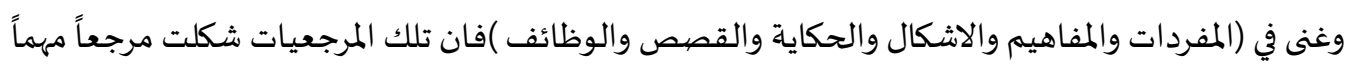

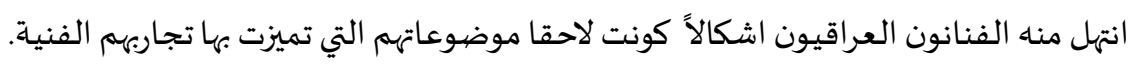

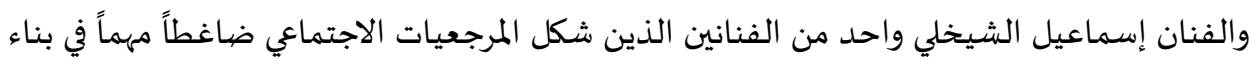

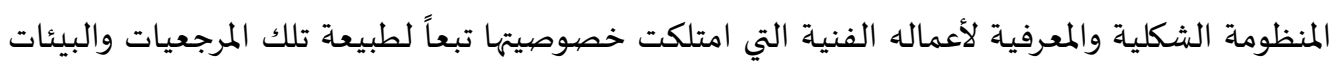

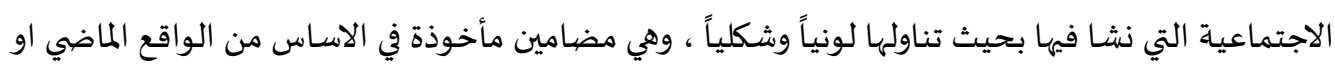

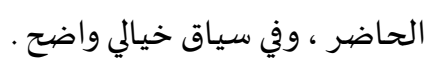
و قد نشأت مشكلة البحث الحالي في الاجابة عن التساؤل الآتي:-

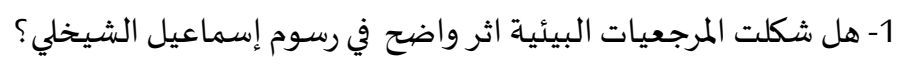

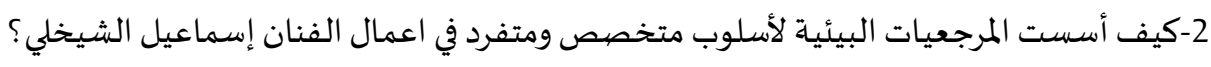
أهمية البحث التث

تفيد الدراسة الباحثين والدارسين والمهتمين في مجال الدراسات الفنية والتاريخية، كما يفيد البحث الحالي المئي الطلبة والفنانين المهتمين بدراسة الفن التشكيلي وفق الأطر الجمالية . هدف البحث

يهدف البحث الى التعرف على المرجعيات البيئية الضاغطة في تأسيس الأنظمة الشكلية في اعمال إسماعيل

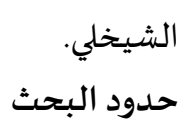

ا-الحدود الموضوعية: المرجعيات البيئية وأثرها في رسوم إسماعيل الشيخلي.

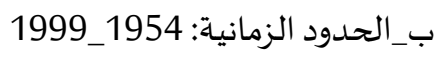
ج_الحدود المكانية: العراق 
محمـل مشيعل حبلب

ISSN(Online) 2523-2029, ISSN(Print) 1819-5229

المرجعيات البيئية في رسوم إسماعيل الشيخلي. مجلة الأكاديمي-العدد 94-السنة 2019 تعريف المصططحات: ( المـرجـع) لغوياً : لغريف

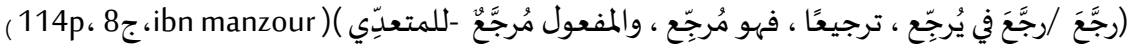

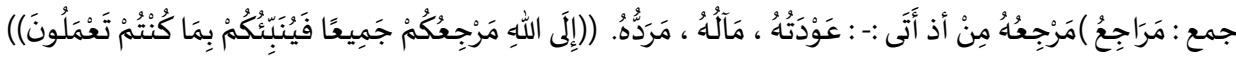

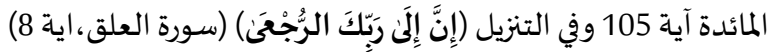

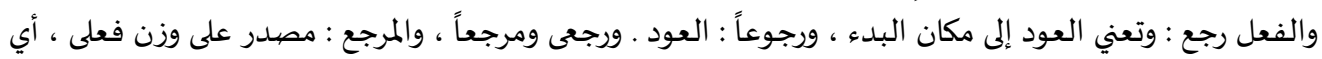

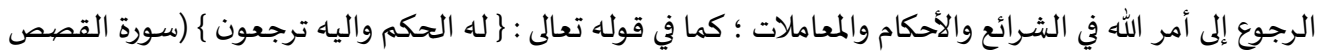

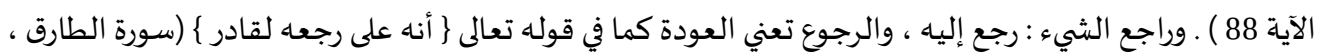
آية 7) أي إعادة الشيء إلى أصله الأول. اصطاحاً

هو البيئة الاستعارية التي تعود اليها جميع محمولات الشكل والرمز وإعادة انتاجها بشكل يتناسب مع طبيعة الخطاب

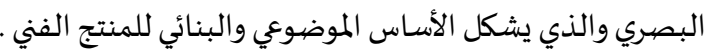

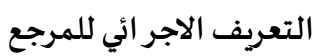
هي عملية استلهام للبنى الشكلية والفكرية التي تجمع بين ادراك الاشكال حسياً وبين الأنشطة الاجتماعية في كل مجتمع والتي يمكن الاستفادة منها في تقديم جماليات فنية تعكس تأثر الفنان في بيئتها.

\section{الاطار النظري \\ المبحث الأول :المرجع البيئي}

هي الخصائص والمميزات للفعاليات الحياتية الإنسانية في مختلف العصور تحدث المباث انطباعا ضاغطاً في

نفسية الفنان تنعكس على السطح البصري بعد استعاراتها من الصور الذهنية المتشكلة في الفكر والمخيلة.

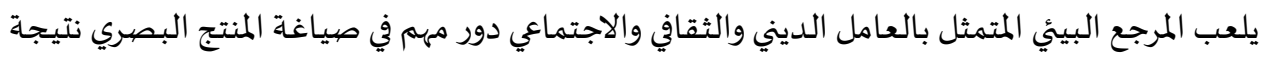
التفاعل بينه وبين الفنان اضافة التراكم المعرفي لدياه في صياغة إنجازاته الفنية وبالتالي ينتج عنه هوية

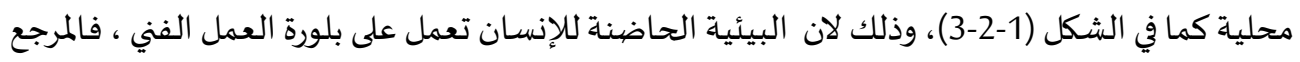
الاجتماعي يربط الفنان مع مجتمعاه وبذلك يكون المنتج لصالح المجتمع الذي يسجل الفنان انتمائه لله

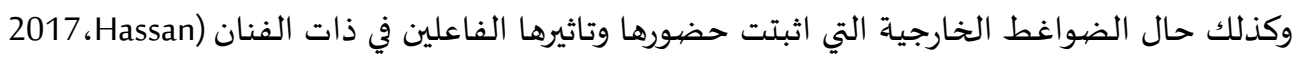

. (35-34p،

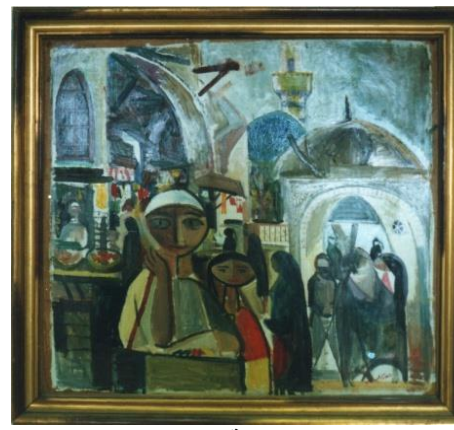

شكل (3) زيهة سليم

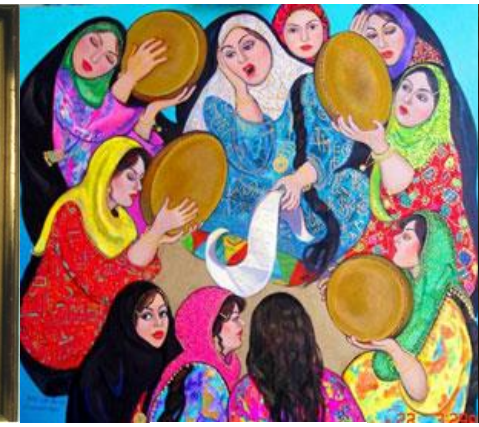

شكل2 وسماء الاغا

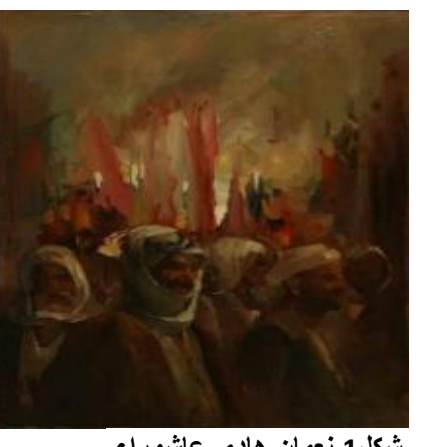

شكل1 نعمان هادي عاثوراء 
أذ من الواضح إّن أهم المقومات الحضارية التي ساعدت على نمو الشعوب وتطورها هو مرجعياتها

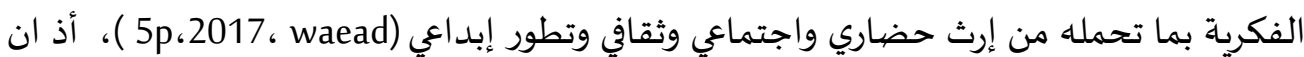
العودة للموروث كما في أعمال جواد سليم وحافظ الدروبي شكل (4-5)، ماهي الا للبرهنة على قيمة الماضي ،ذلك لان اكتشاف الذات يتطلب معرفة الجذور ، لقد وجد الفنانين العراقيين في الموروث

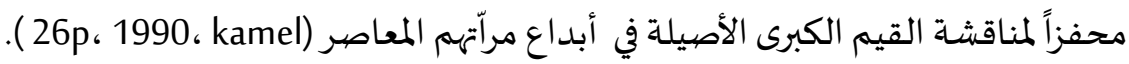

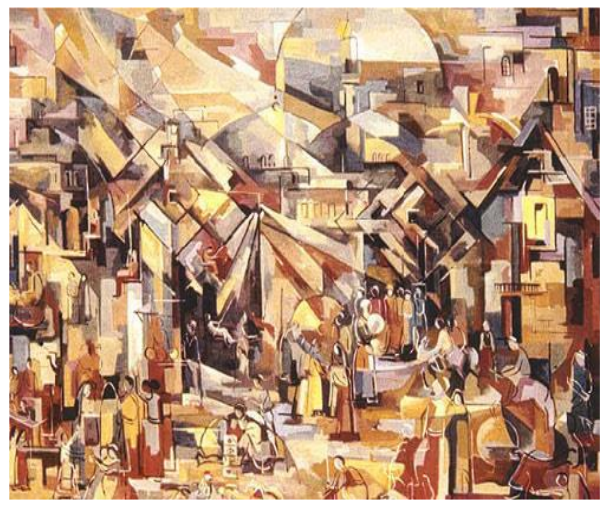

شكل (5) حافظ الدروبي

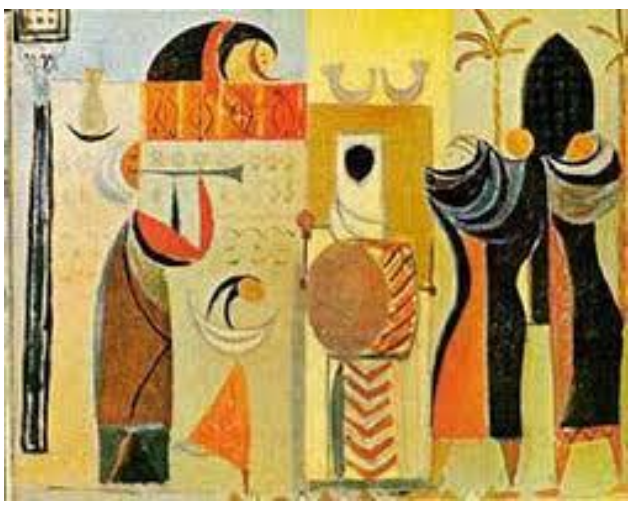

شكل (4 )جواد سليم

مفهوم البيئة

ان الفرد يستجيب الى تكيف الجماعة بيئياً، اذن ان التفاعل يشكل عامل رئيسي في تشكيل العادات

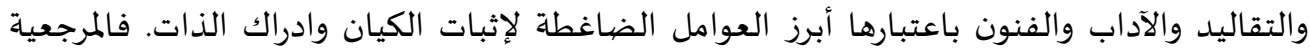

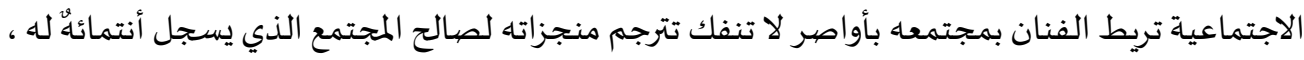

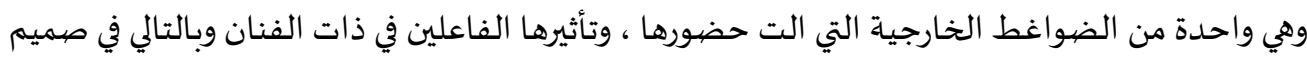

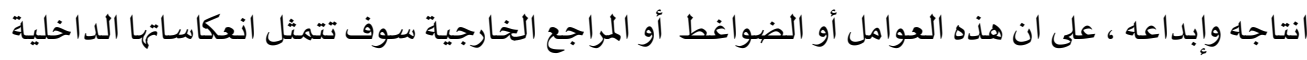

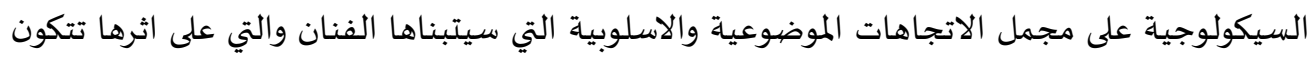

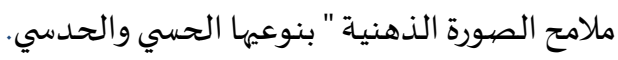

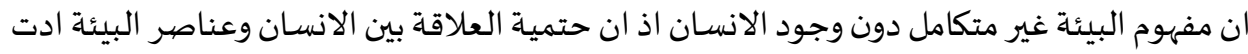
الى ظهور نظم وانساق ساهمت في تلك المتغيرات باختلاف معطيات البيئة اذن ان الكائن البشري يتفاعل

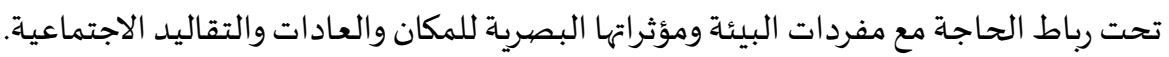

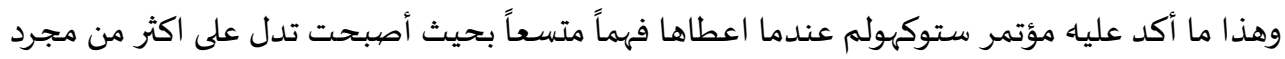

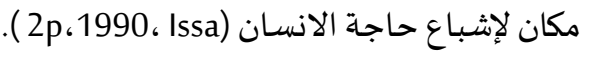


ومن الواضح أن أهم المقومات الحضارية التي ساعدت على نمو الشعوب وتطورها هو مرجعياتها الفكرية بما

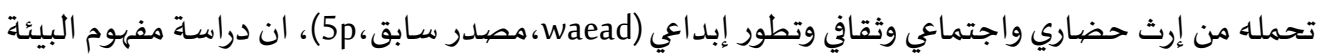
يضعنا أمام نوعين من البيئات هما البيئة الطبيعية والبيئة البشرية.

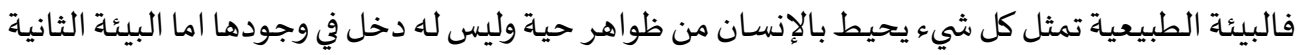

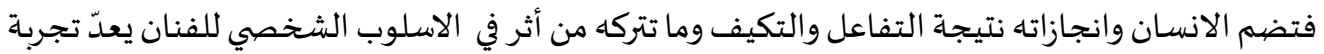
تتعرض لتراث انساني واسع وخصب وتراكم عبر محاولات وخبرات الفنان، الذي أغنى اعماله بمشاعر أصيلة

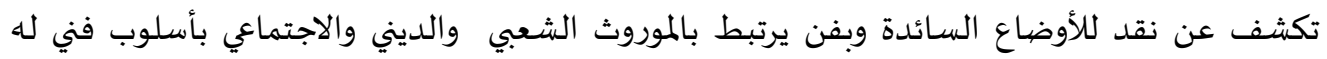

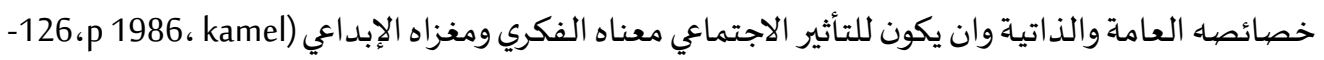

فضلاً عن ذلك فان الفن وسيلة لتحقيق المشـاركة الوجدانية والتعاطف بين الأفراد فتضيف خبرة " التعبير عن طريق الفن سلوك يسلكه الإنسان ، وهو شيء فطري يدعما استعد اد اد الفرد وموهبته .

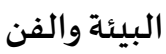

ترتبط البيئة بالفن ،فتأريخ الفكر الفلسفي زاخر بالشواهد والآراء التي تكشف لنا صيخ ذلك الارتباط ، منها ما ذهب اليه (أرسطو)( ينظر haider،

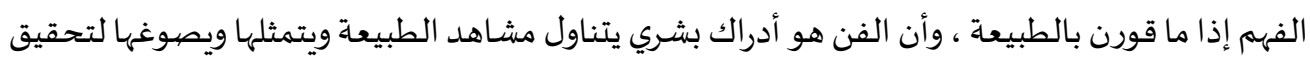

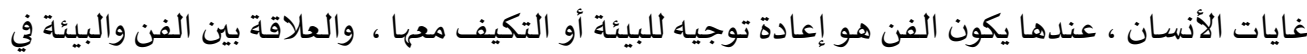

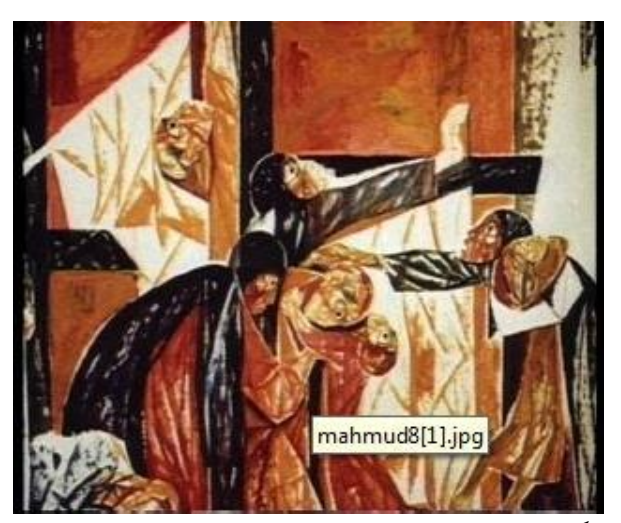

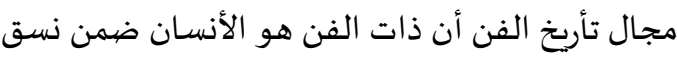

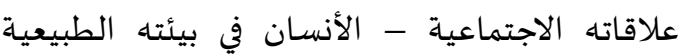
والاجتماعية - أذ يعيد بالفن أنتاج الواقع (الطبه الطبية

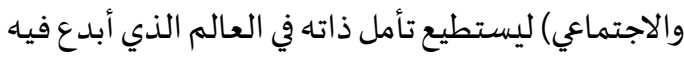

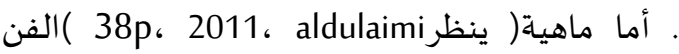
والأبداع جاءت لتؤكد على الجانب الانفعالي للفنان الذي يتقرر على وفق تأثير البيئة الاجتماعية شكل(6)التي يعيش في وسطها ، فكلما عكس الفنان الاتجاهات الأساسية لمجتمعها ، كلما كان أكثر إحساساً بنفوذها ، يكون شكل 6 محمود صبري

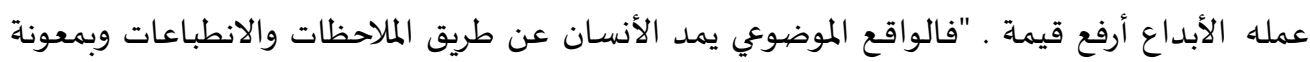

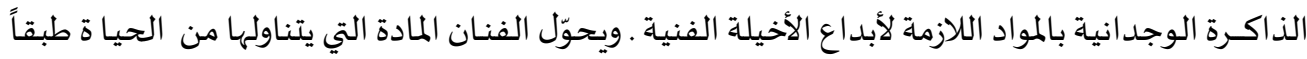

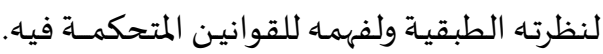
انواع البيئات البيئة هي المكونات والوسط الذي يتفاعل معه الانسان ومؤثراومتأثراً بشكل يكون العيش معه مريحا

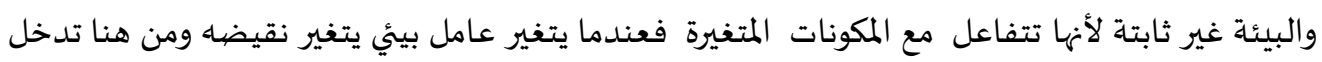

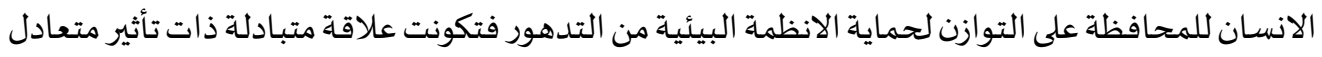


سواء بطابعها الايجابي أو السلبي ، وعليه فان البيئة التي اجتهد الانسان في تكوينها حينا وتكييفها حينا اخر

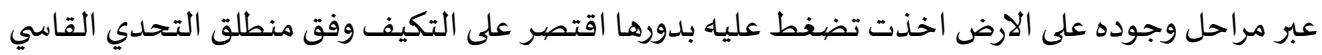

(26p، مصدر سابق ، issa)

البيئة الطبيعية

عند ذكر بلد ما يكون الحديت جميلاً اذا ما اقترن برموز خاصية بهاه من بيئته الطبيعية فتتزين لوحته في الطاهي

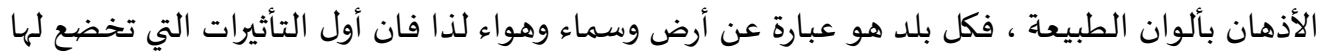

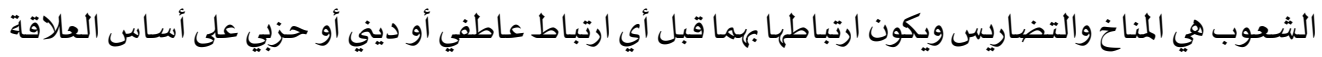

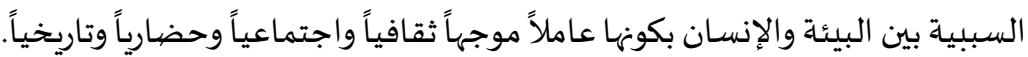

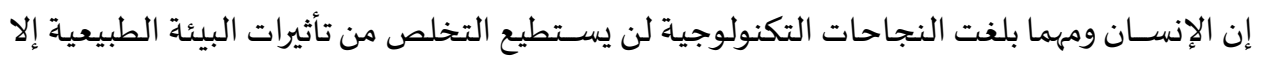

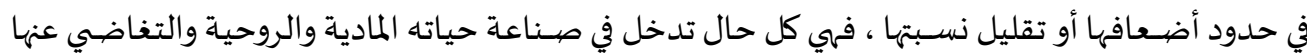

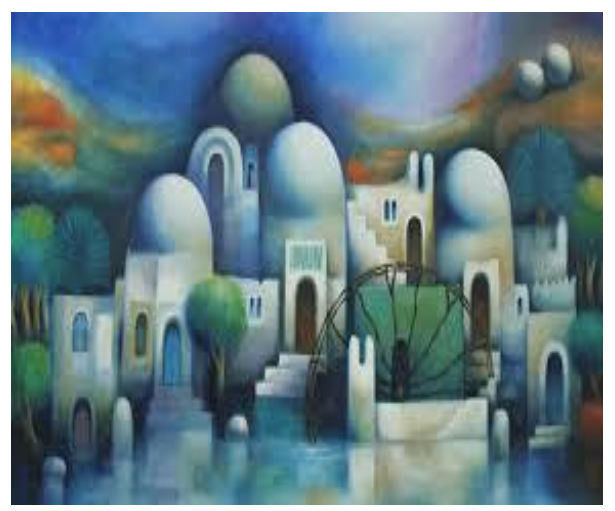

شكل7نوري الرأوي

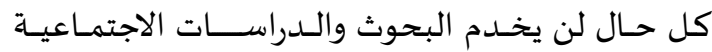
والنفسـية والحضيـارية عن التاريخية ، ونؤيد ما ذهب إليه

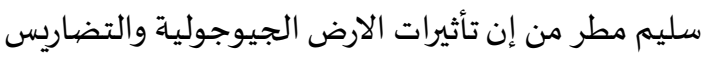
والمنـاخ وطبيعـة المياه والحرارة وحتى الريح والغبار لازالت

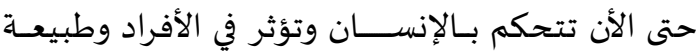
الشـــوب او تتراكم عبر ميراث أجيـالـه رغم كل الثورات

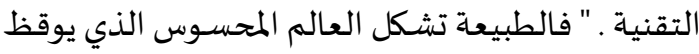
في الأنسـان الأفكار والمشــاعر والخيال الخصسب" والمحفز الأهم في تنشيط الخيال واستدراجـه للفعل الإبداعي .

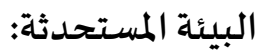

ويقصـــد بها ذلك الجزء من البيئة الذي يتكون من الأفراد والجماعات في شــــل تفاعلهم وأنماط النظم الاجتماعية التي يعيشون فيها وجميع مظاهر المجتمع الأخرى، وتشمل النظم والعلاقات من منات

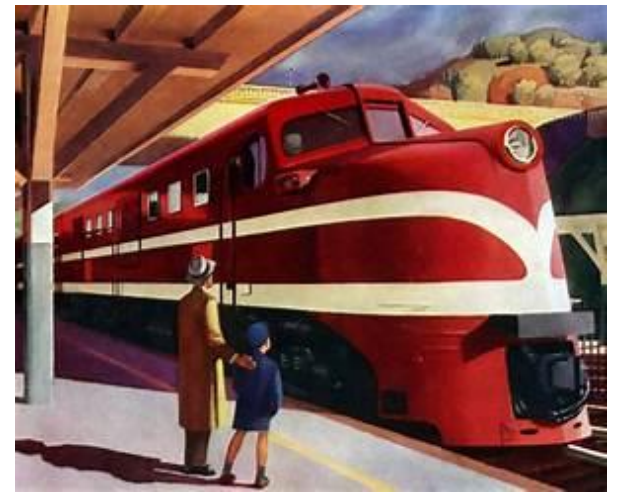

شكل وادورد هوبر

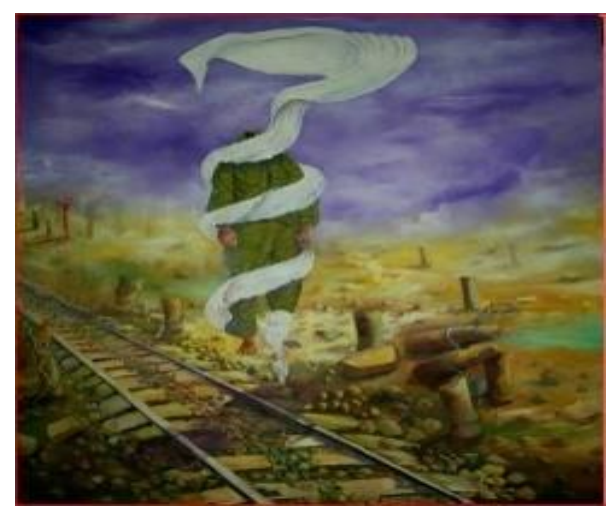

كثكل8 شبيب المدحتي 
التي تحدد أنماط حياة البشر فيما بينهم سـواءاً كانت سياسية أم اقتصيادية أم قانونياة، كما تشمل التهل

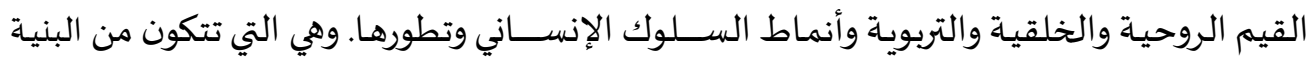

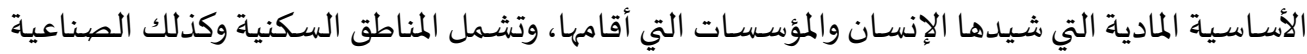

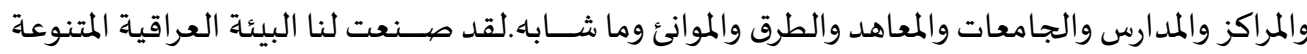

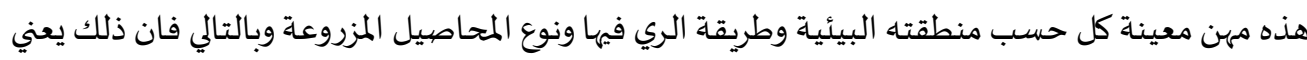

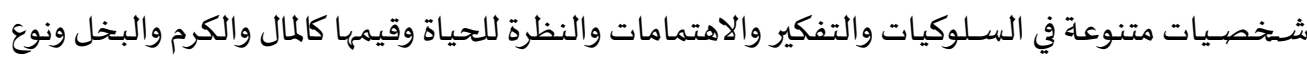
الملبس وأسلوب العيش وغير ذلك( issa، مصدر سابق ، (29p لذا فهي تعد المصدر الأول والأهم لكل فن.

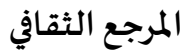

الثقافة هي الطريقة الكلية للحياة في أي مجتمع وتعد النظم الاجتماعية عنصرا من عناصر الثقافة

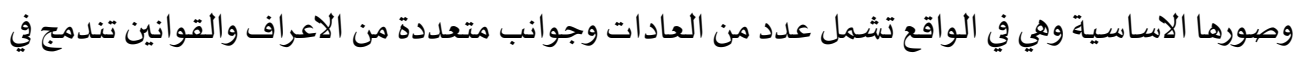

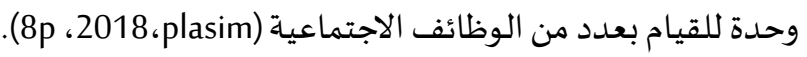

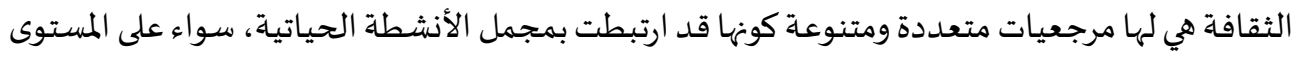

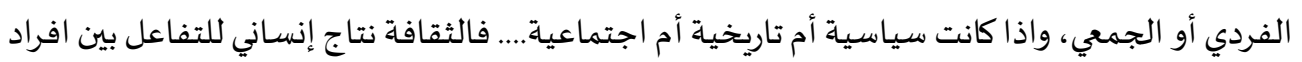

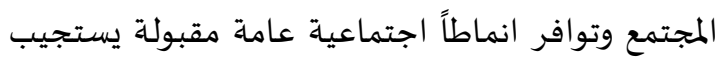

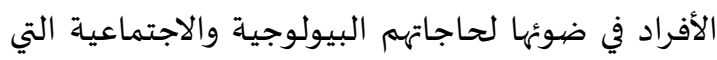

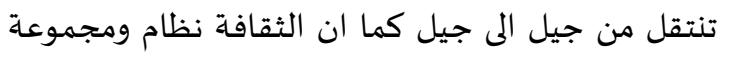

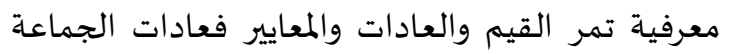
وأفكارها واتجاهاتها تستمد من التاريخ وتنقله الى أجيال

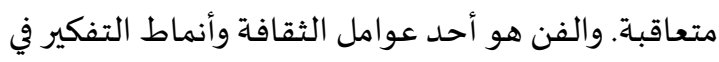

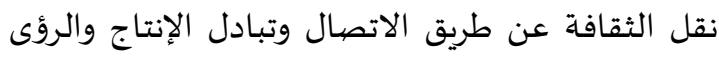

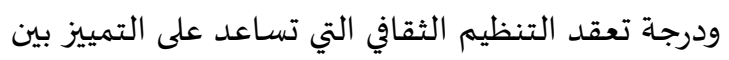

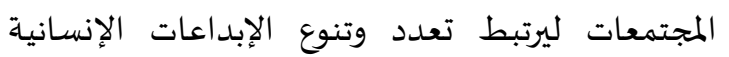

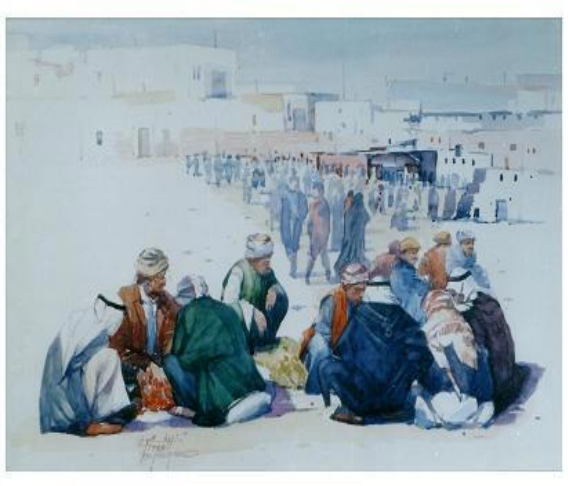

شكل10 سوق الموصل /خليفة محمود

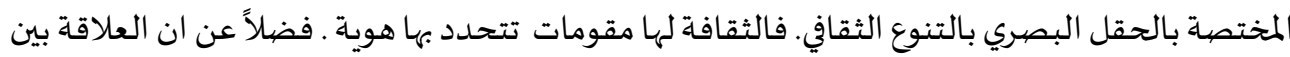

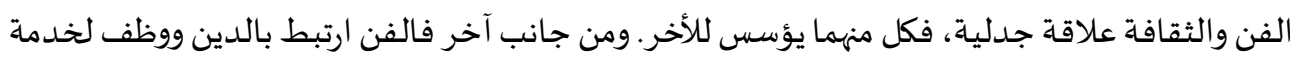

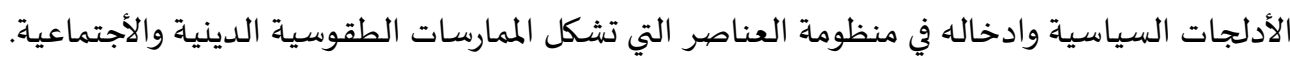

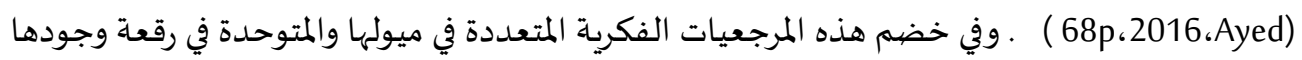

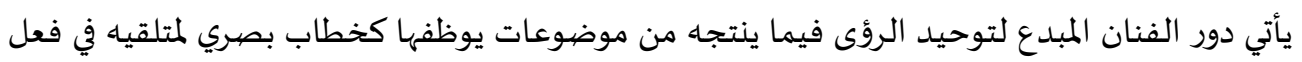

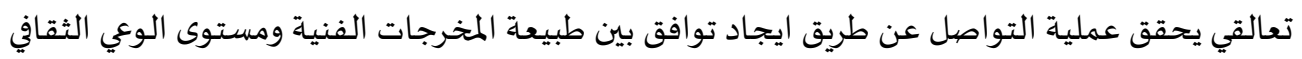

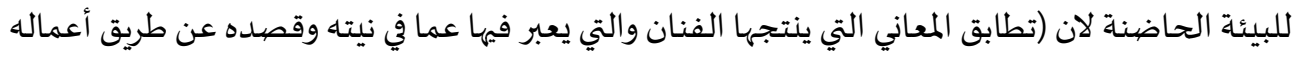

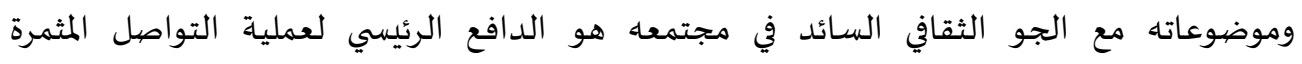

شكل(11،11، 11). 


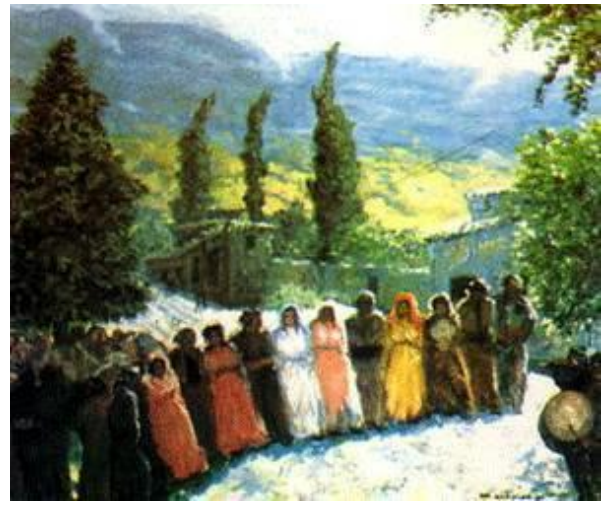

شكل11)دبكة كردية محمد عارف

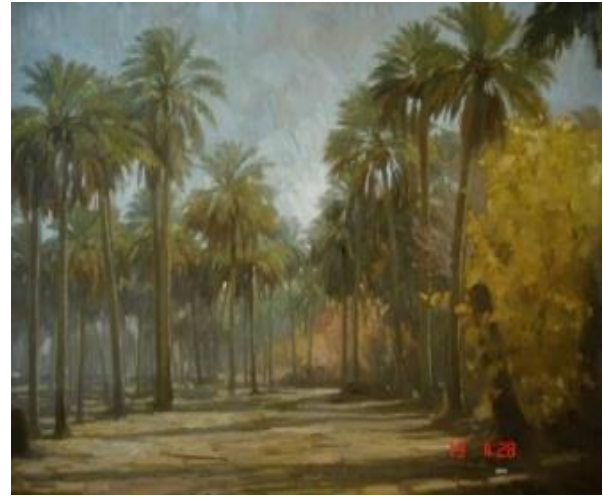

شكل12منظرطبيعي ناظم حامد

\section{المرجع الاجتماعي}

يمثل المرجع الاجتماعي عنصراً أو ضاغطاً يعكس طبيعة وصفات الواقع الموضيوعي الأكثر تأثيرا في صياغة وترسيم التجربة الفنية ، ونحن بصدد قراءة هذا المرجع ومعرفة ابعاده لابد من سبر اغواره كعلم مستقل (Sociology)

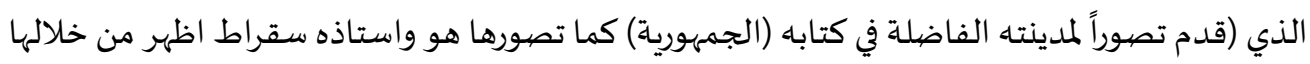
دراسـة مفصلة عن قضايا المجتمع ، دالا بالذكر ان المجتمع مكون من انظمة متصلة وهي النظام السياسي

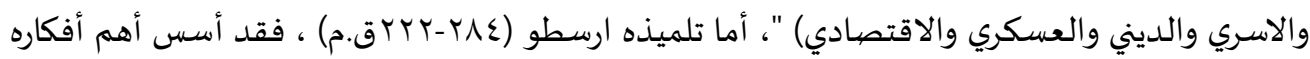

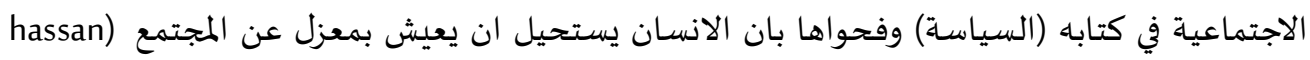

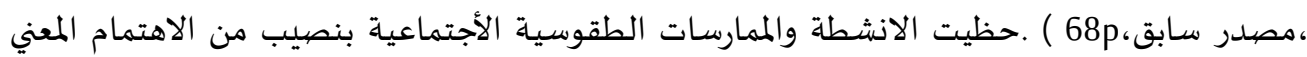

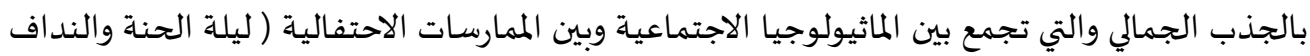
) من قبل الفنان العراقي، ان صياغة هوية فنية جديدة تعبر عن ذات الفنان واتجاهـه ضيمن حقل الفن فضيلاً

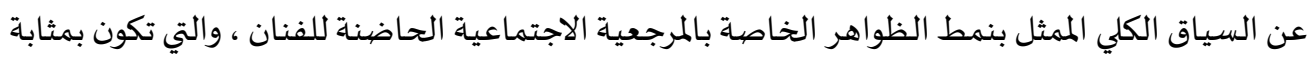

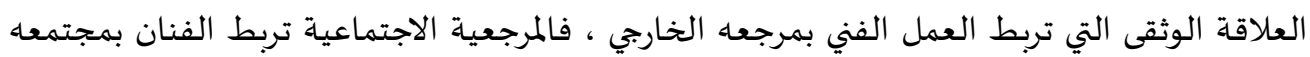

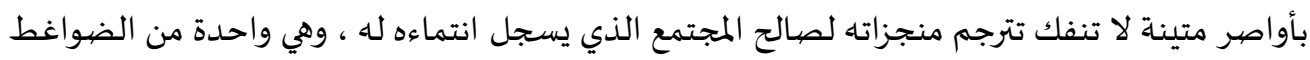
الخارجية التي اثبتت حضورها ، وتأثيرها الفاعلين في ذات الفنان .شكل (14.13 ). 


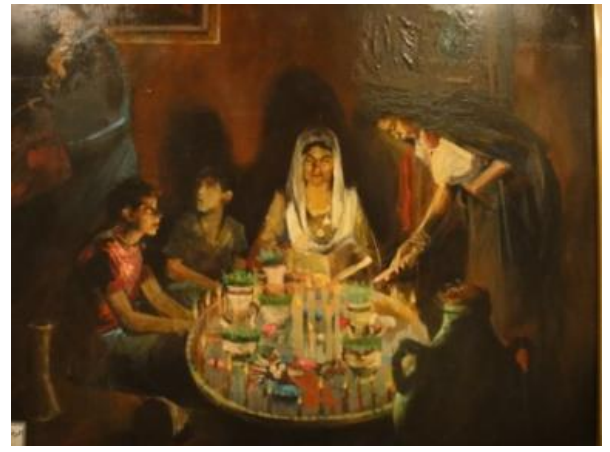

شكل 14 ليلة الحنا نعمان هادي

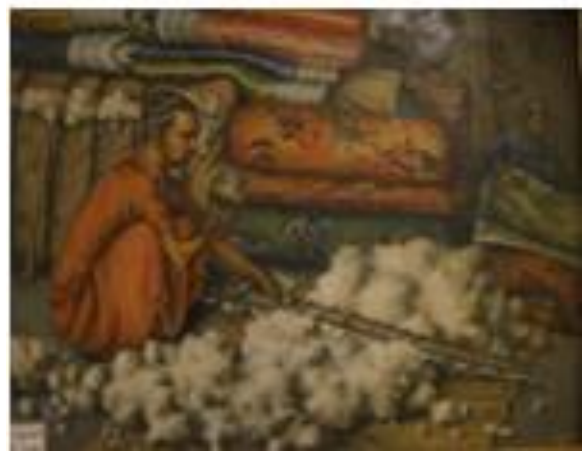

شكل 13النداف /شاكر الثاوي

وبالتالي في صميم انتاجه وإبداعهه ، على ان هذه العوامل ، أو الضواغط ، أو المراجع الخارجية سوف تتمثل

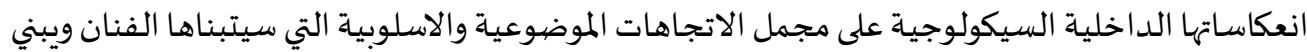
على اثرها ملامح الصورة الذهنية " بنوعيها الحسي والحدسي ، والمتولدة اثر تداخل العوامل النفسية من بواعث وانفعالات وعواطف وميول ورغبات مكبوتة مع ما تتلقاه المدركات الحسية من ايقونات خارجية تمثل فئل

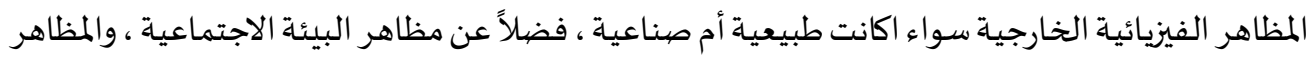

الثقافية العامة. المرجع التاريخي

للبيئات المختلفة التي احتك بها الفنان وتأثر بها مشكلة بالنتيجة ميكانزمات تفاعل تعتمد موقف الماتف

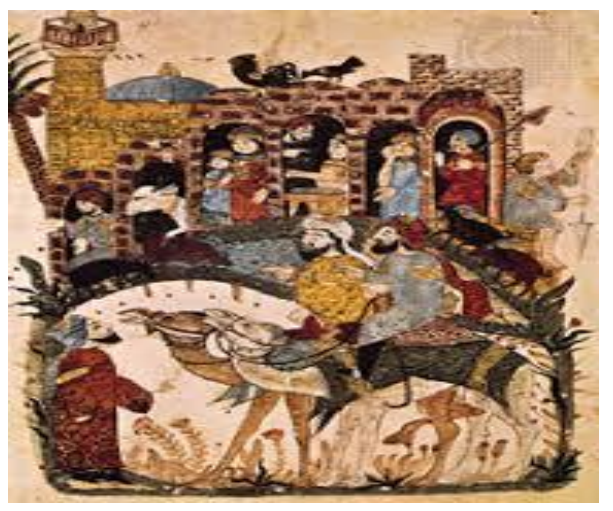

شكل14منمنمات الواسطي

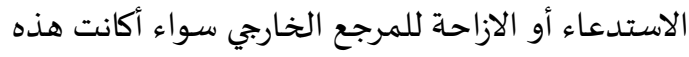

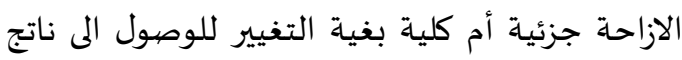

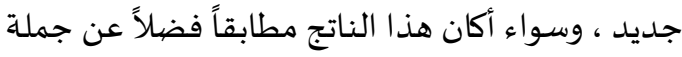
الشروط البيئية الشاملة هي التي تعمل على قيام نمط

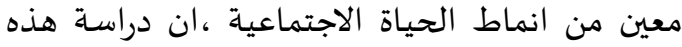

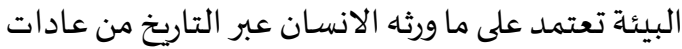

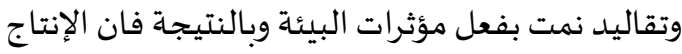

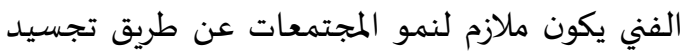

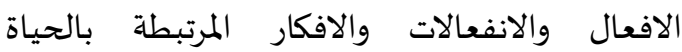

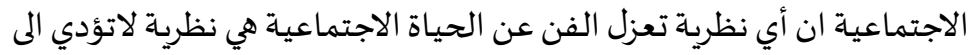
مزيد من الفن وتطوره بل تؤدي الى عكس ذلك (1972،finkelshtein، 1972 شكل (14) وعلى هذا الاساس فان دراسـة الاعمال الفنية للفنان اسماعيل الشيخلي تكشف عن عيش حياته وما يشكله الفنان من اهمية في صياغة التأثير وفي اسلوب تعبيره أي من غير الفصل بين الفرد وبيته الاجتماعية. كما هو الحال في رسوم الواسطي الذي القى الضوء على الكثير من تفاصيل العلاقات والعادات السائدة في

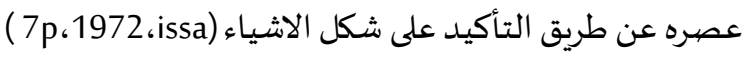


لايقل تاثير المرجعية الدينية على الفن واسـاليبه التعبيرية عن غيره من المرجعيات بل ان علاقة العقيدة

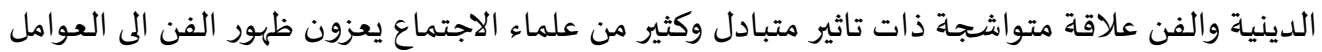

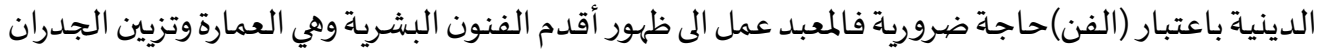

بالنقوش. (94p، 2018haider). تعد البيئة الدينية احدى الوسائل الدفاعية لدى الانسان الأول تجاه الهوة بينه وبين موجودات البيئة

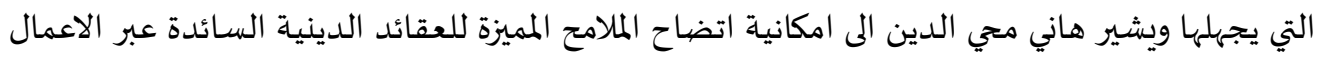

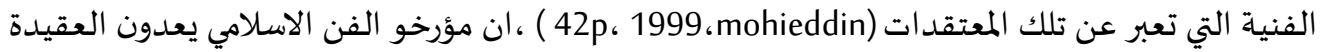

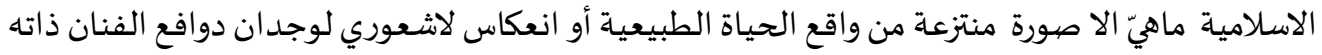

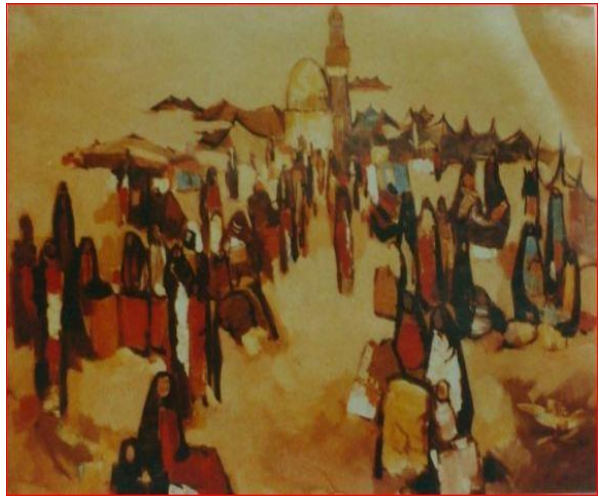

شكل 15 العودة من الزيارة سماعيل الشيخلي

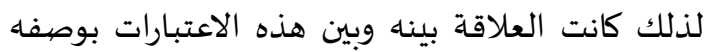
فلسفة للحياة ونظام للمجتمع وتظهر مؤثرات البيئة الدينية في الفن التشكيلي عن طريق الزخارف والنباتات والتي تم توظيفها في المآذن والقباب، استمّرَ الفنان التشكيلي في تجسيد الناتج الفكري عن طريق تصويرهُ ؛

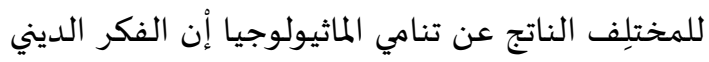

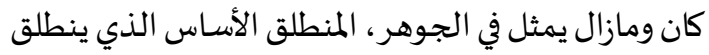

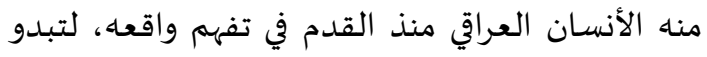
مفاصل الحياة في تواجدها وحركتها وتقييم العلاقة فيما بينها بدلالة قوى إلهية)دينية، شكل(15) المرجع التر اثية

التراث هو ذلك الحضور المتجدد مع كل جيل أعطى لوجوده الديمومة المترابطة بديمومة الانسان الذي

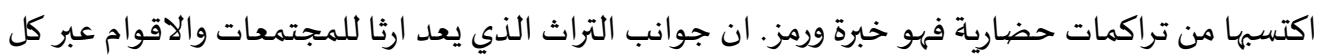

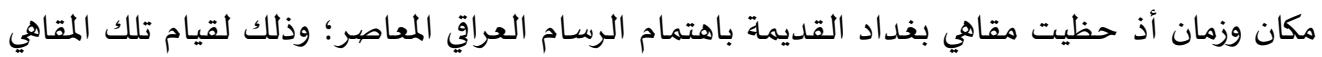

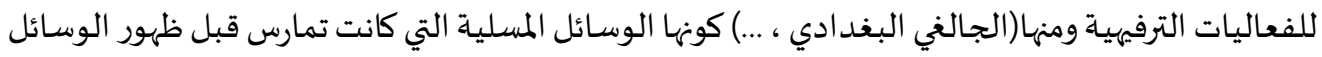

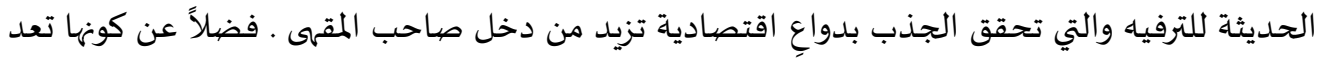
ملتقى للمثقفين الذين يستمتعون بمناقشة المواضيع المرتبطة بضواغط المحيط البيئي ومنها السياسية

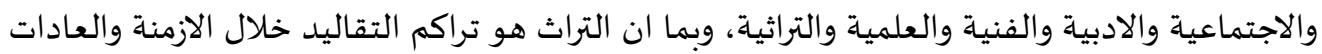

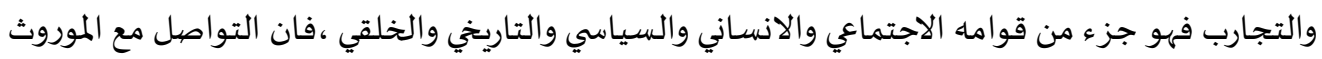

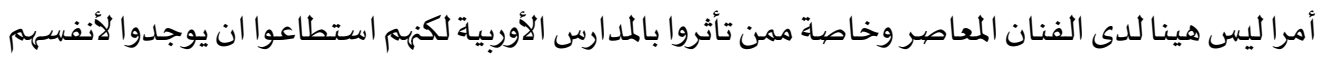
شخصية لا تنفك عن السياق العام للتراث العربي الاسلامي وتستلهم منها رؤيته ، ومن هنا استطاع الفنان

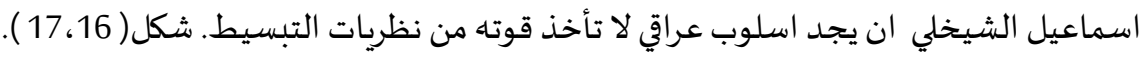




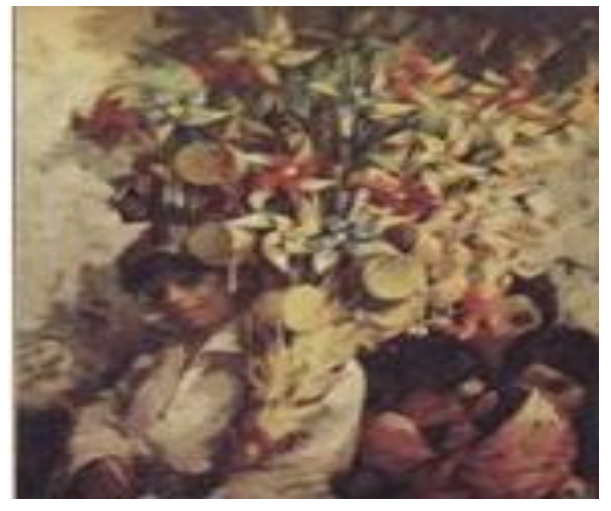

شكل 17 بائع الفرارات نجيب يونس

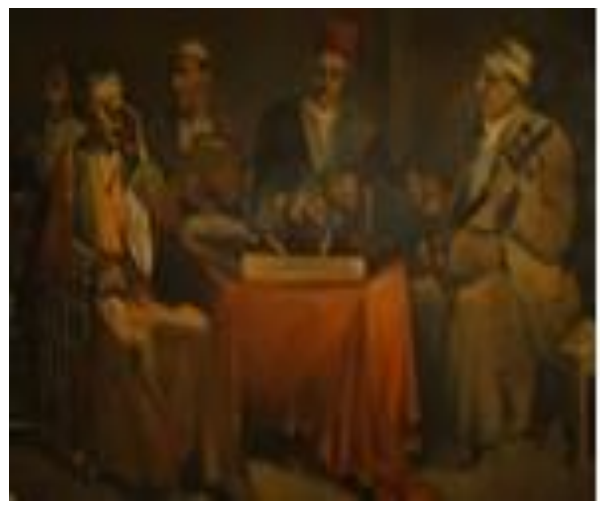

شكل 16 الجالغى البغدادي علاء شبلى

$$
\begin{aligned}
& \text { مؤشرات الاطار النظري } \\
& \text { 1- يخضع المنتج الصبوري المى تأثيرات المرجع البيئي وتفاعل الانسان معه. } \\
& \text { 2- للجوانب الفكريـة أثر في شخصية الفنان واسلوبها وطريقة توظيف المفردات. } \\
& \text { 3- العودة للموروث للبرهنة على قيمة الماضي وجعلها محفزا للقيم الاجتماعية. } \\
& \text { 4- تعد الانعكاسـات السيكولوجيا أثر في الاتجاهات الاسلوبية والموضوعية. } \\
& \text { 5- يشكل الفن بصفة عامة حقلاً ثقافياً له دور في فهم وادراك جماليات البيئة. } \\
& \text { 6- حظيت الأنشطة والممارسات الطقوسية الدينية والاجتماعية باهتمام الفنانين العراقيين. } \\
& \text { 7- الرمز والدلالة الرمزية كان لها حضيور واضح في الفن العراقي. } \\
& \text { 8- الموروث الاجتماعي والفلكلور لله الأثر في المجتمع فهو يختلف حسب الزمان والمكان. } \\
& \text { مجتمع البـحث }
\end{aligned}
$$

نتيجةة لسعة الاعمال الفنية واتساع المرحلة الزمانية فقد تعذر جمع هذه الاعمال من فترة (1945-1999) لذا يتكون مجتمع البحث من بعض ما أنتجه الفنان من أعمال والتي أمكن الحصيول على البعض منها من مصيادر الرسائل الجامعية والفولدرات الخاصية بالفنان ومن الشبكة الالكترونية . وقد حاولت الافادة منها بقدر أهد اف البحث ومشكلته وقد غطت هذه الاعمال الحدود الزمانية والموضيوعية. عينة البحث

تم انتقاء نماذج عينة البحث بشكل قصدي بما يتلاءم مع عنوان البحث، وذلك باختيار ثلاث اعمال نفذت ، وبحسب التسلسل الزمني، وقد اختيرت العينة على وفق المسـوغات الآتية :1- تقع الاعمال ضمن الحمدود الزمانية للبحث .

2- تعطي النماذج المختارة للباحث فرص في دراسـة المرجعيات البيئية (الثقافية والدينية، الاجتماعية) 
اعتماداً على المرتكزات و مؤشرات الإطار النظري والتي شملت الأطر الفكرية والفلسفية والجمالية

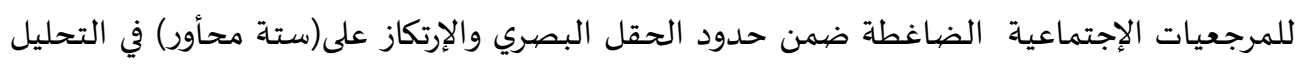

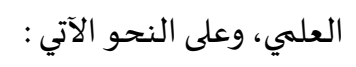
الوصف البصري ، أنظمة التكوين ، تقنيات الإظهار، المرجعيات الضاغطة، الأسلوب ، المرجعيات

$$
\text { الاجتماعية البحثة }
$$

أعتُمِدَ المنهج الوصفي التحليلي في تحليل نماذج عينة البحث .

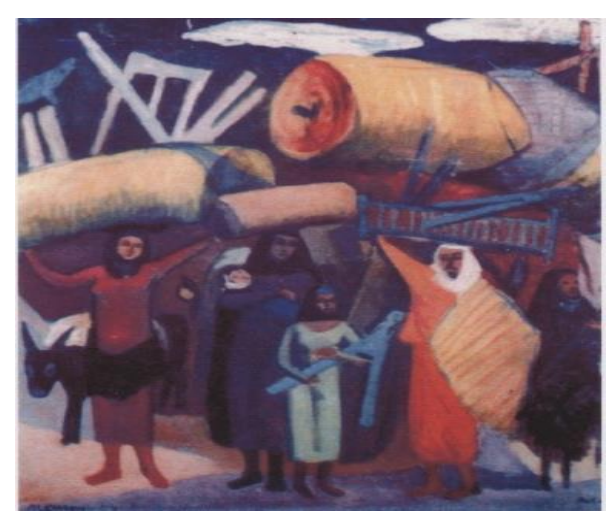

$$
\begin{aligned}
& \text { تحليل العينات } \\
& \text { اسم العمل الفني: الفيضيان }
\end{aligned}
$$

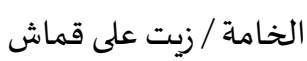

$$
\begin{aligned}
& \text { العائدية /العراق /لاق } \\
& \text { القياس/ بلا } \\
& \text { تاريخ الانجاز: } 1954 \\
& \text { الوصف البصري: }
\end{aligned}
$$

لوحة مستطيلة الشكل بالوضع العامودي

ذات مسقط افقي في وضع استعراضي لسبعة اشخاص، محتشدين مزدحمين في الحيز المكاني وكأهها عمل

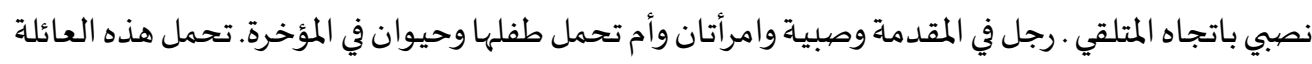

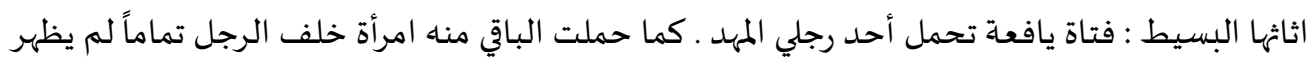

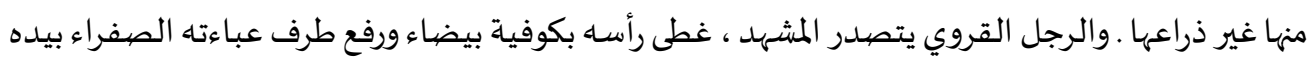

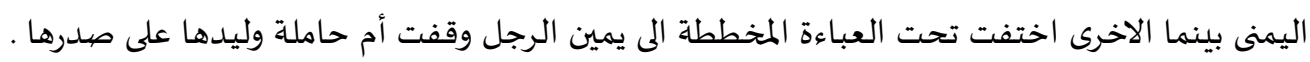

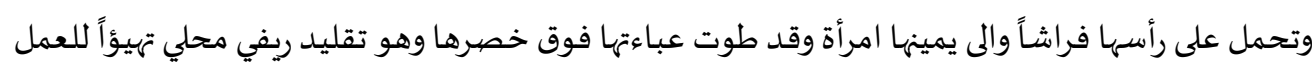

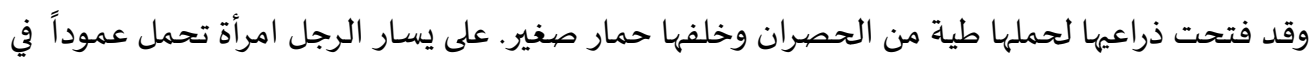

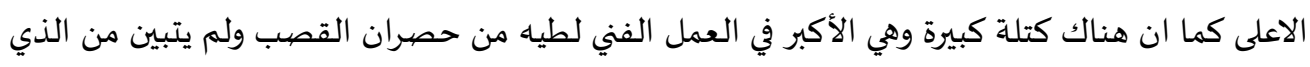

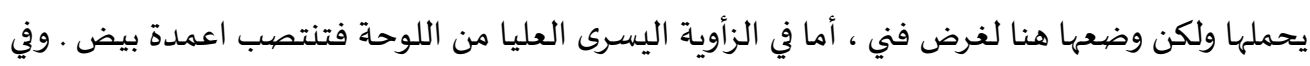
حافة اللوحة العليا غيمتان بيضائتان ـ وقد استطاع الفنان من تجسيد هوضية محلية للأشكال وأوضاعها.

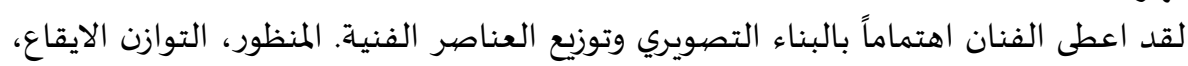
تقنيات الاظهار: - ت تلوحة العليا

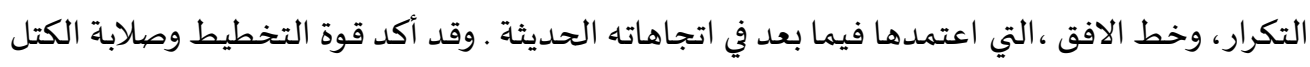

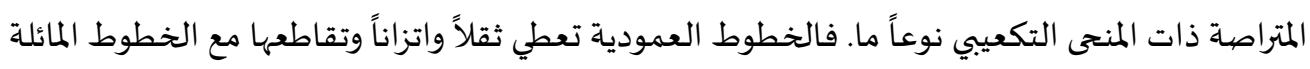
تعطي حيوية وحركة خفية كوضع المهد والاعمدة المائلة في الاعلى وفتح وحركة الذراعين ، توزيع الكتل 
والمساحات المضيئة تشكل مركز سيادة ومهيمنة كبرى على شكل مثلث مقلوب الرأس يبدأ بالرجل وتنتهي

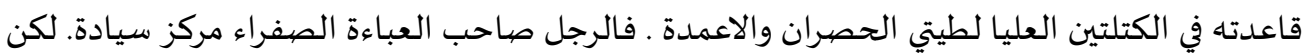

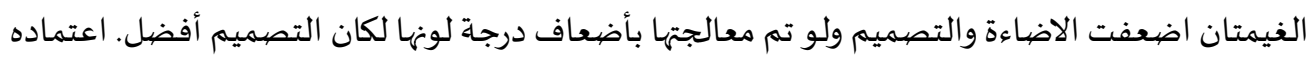
الالوان الحارة ذات المذاق اللاذع في المستويات المتقدمة (الاشكال) والخلفية الزرقاء أعطى تضياداً ودرامية . البرتقالي والاصفر والاحمر المحروق والبني والابيض تقابلها الازرق الفاتح والغامق والبنفسجي ولكنها مشبعة هي الاخرى من الالوان الحارة 000 فالوانه شرقية محلية مستمدة من الفلكلور الشعبي (البسط والسجادياد).

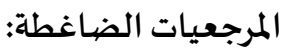

ان مأساة الفيضيان كانت تتكرر كل عام جارفة البيوت الطينية (والصرائف) للعوائل المهاجرة الى بغداد

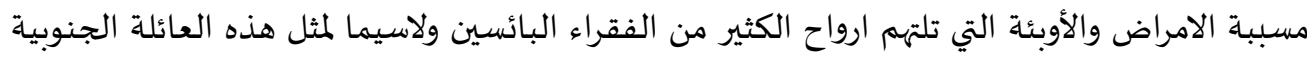

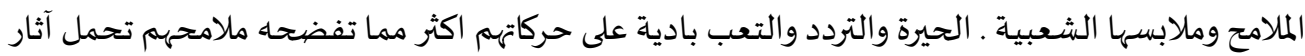

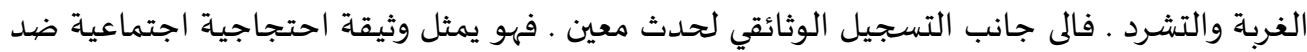

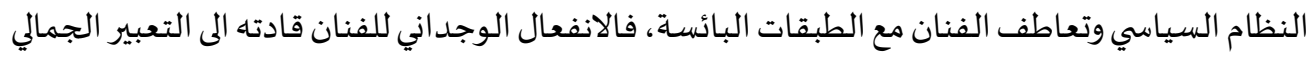
، فهو ليس رصداً بصرياً لحدث واقعي . بل يقدم مقطعاً أو شريحة من بؤس وغرابة مجتمعة في المرحلة التي

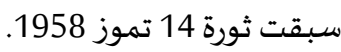

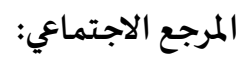
استطاع الفنان إسماعيل الشيخلي من تجسيد واقعة مأساوية مرت بها بغداد في لوحة فنية بكامل حيثياتها

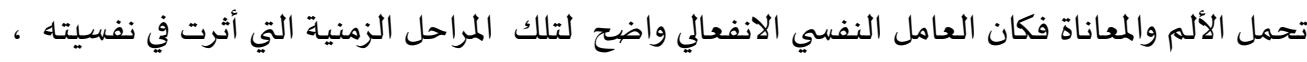

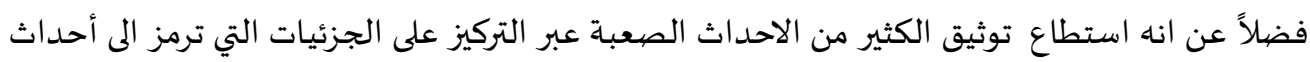

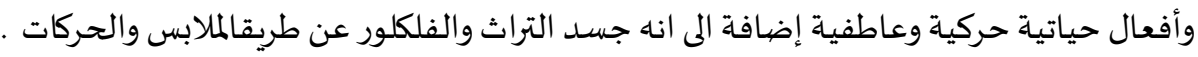

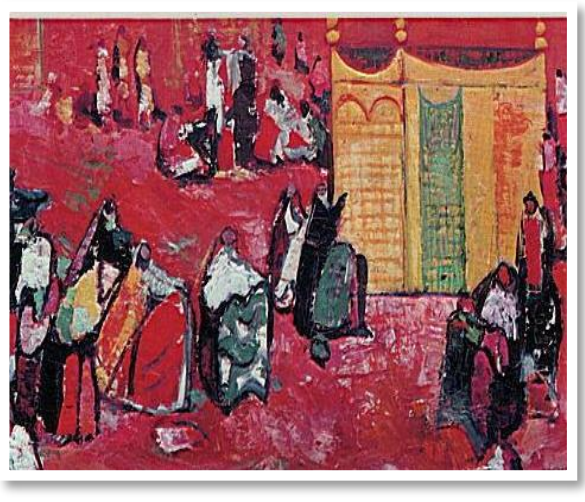

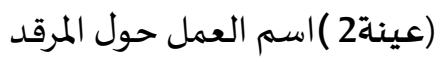
الخامة /زبت على قماش القياش القياس/120×90 تاريخ الإنتاج/1961 القياس/بلا

\section{الوصف البصري :}

لوحة مسـتطيلة المشـهد الفني فيها عبارة عن الهيئات

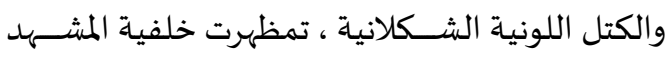

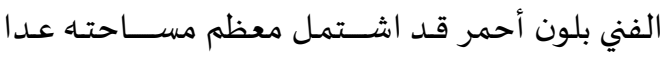
بعض المسـاحات باللون الأصـفر الفاتح والرمادي ـ فيما ركز الرسـام على مفرداته التي اشـتملت على إظهار قيمة كل من الضريح والنساء الزائرات . تقنيات الاظهار:

تشات كل الشخصيات (الرجال والنسوة) بكتل لونية أفصحت عن حركات الشواخص بديناميكية جميلة 
ISSN(Online) 2523-2029, ISSN(Print) 1819-5229

مجلة الأكاديمي-العدد 94-السنة 2019

وأثبت انسسجامها مع أسـلوبية العمل الفني فضيلاً عن ما نجدة من توازن بصـري في إنشـائية عناصـر المشهـد

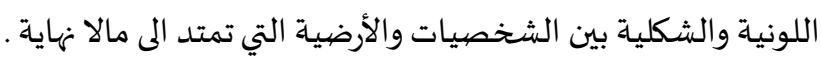

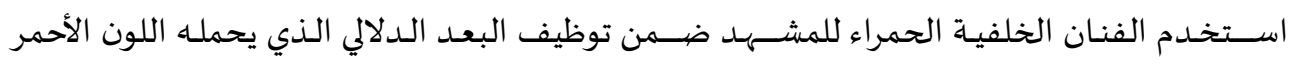

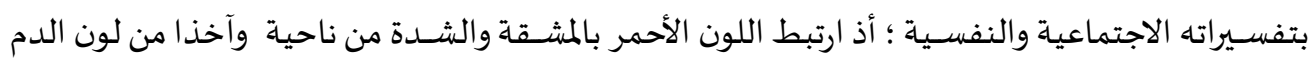

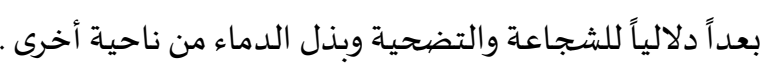
المرجعيات الضياغطة: يتفرد المشهد من هذا المنطلق بخصوصيات بيئة ترتكز على دعامات اجتماعية ، قد احتضنت أعراف وتقاليد

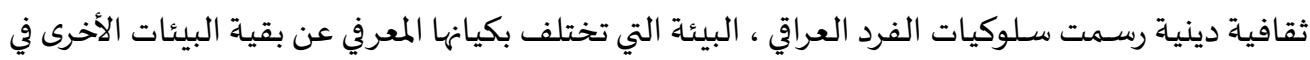
العالم . كما اتسـم المشهـد برؤى جمالية وقيمة دلالية أحيطت بأطر وانسـاق تمثل الخطاب البيئي الإنسـاني

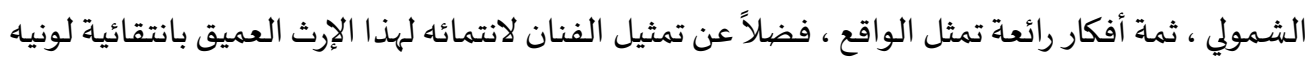
وشكليه باهرة.

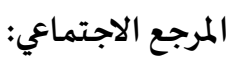
استطاع الفنان إسماعيل الشيخلي ، ان يحاكي حالة متأصلة في المجتمع العراقي عن طريق الابنية، والازياء،

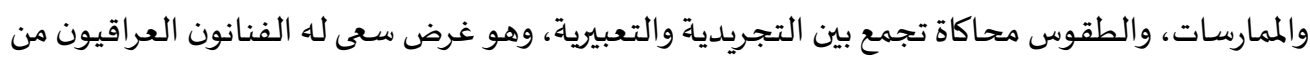
اجل اثبات هوية فنية تتمظهر بها هذه الطقوس العقائدية الخاضعانة للمرجع الديني والاجتماعي

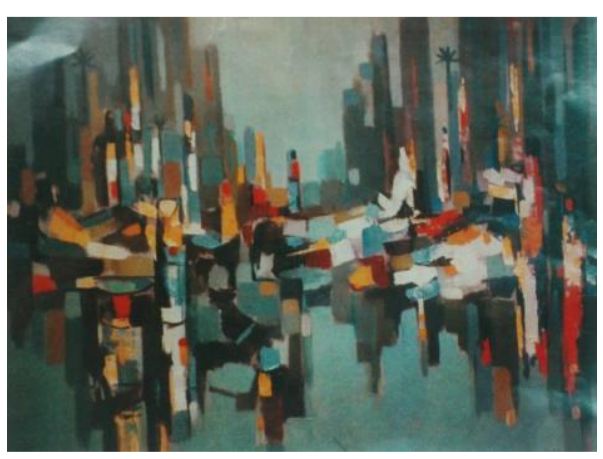

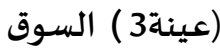

التاريخ 1975 المادة : زيت عمى قماش القياس 91×91 111 سمر الوصفف البصري : سطح بصري مستطيل ذو مسقط أفقي تتشكّل مفرداته البنائية من توظيف الشكل الهندسي توظيفاً

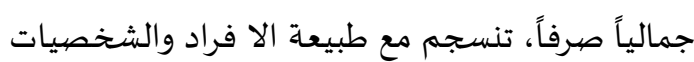

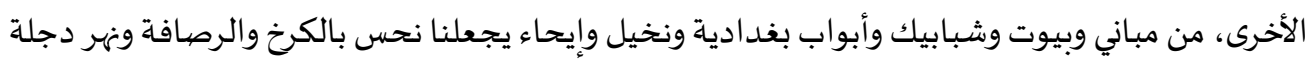

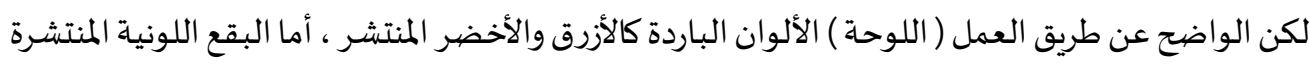

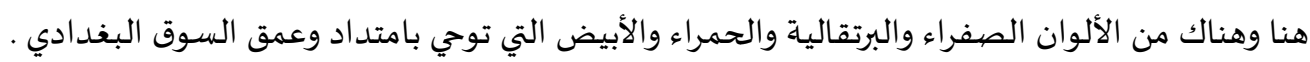

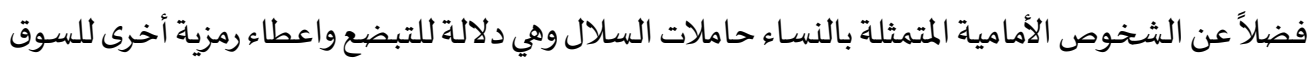

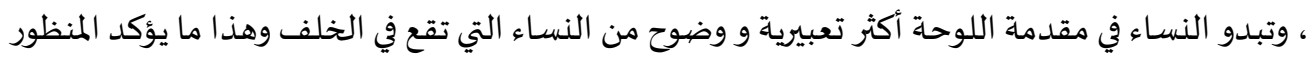

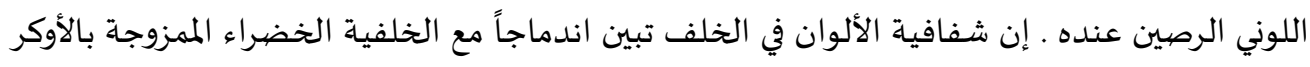
كترابط عضوي لوني وثيق يؤكد ارتباط الفرد بالبيئة والواقع . 


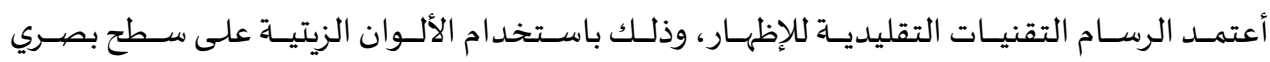

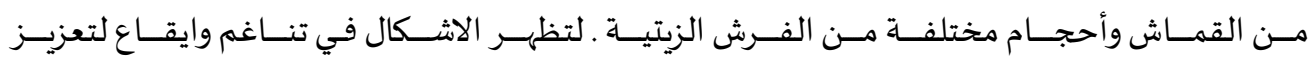

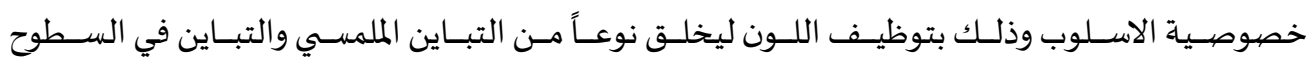
والتباين في الكتل التي تتكون منها المفردات البنائي المرجعيات الضياغطة:

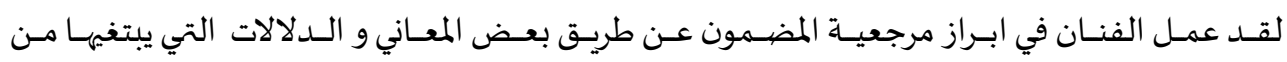

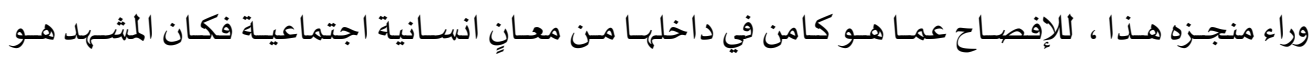

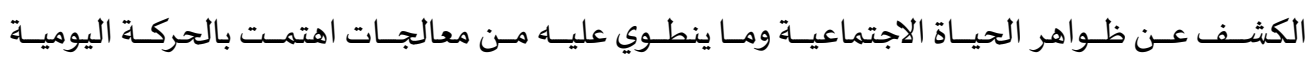

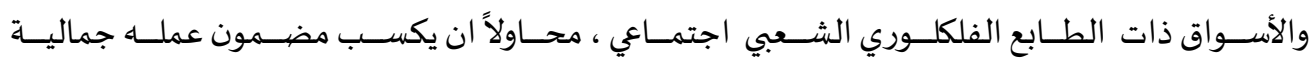

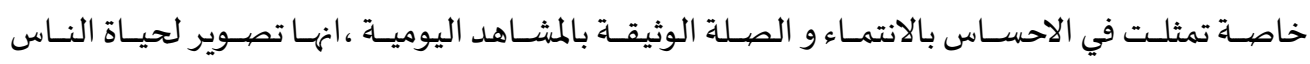

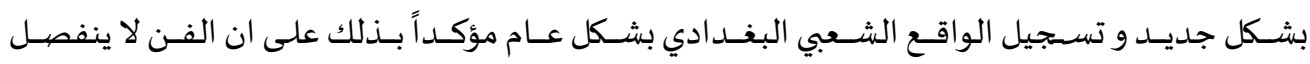

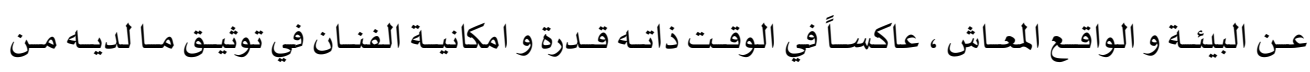

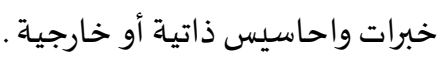
المرجع الاجتماعي

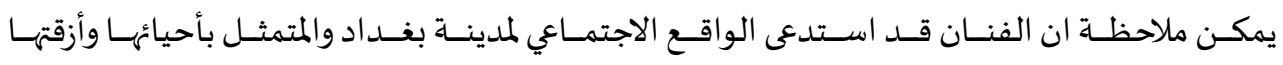

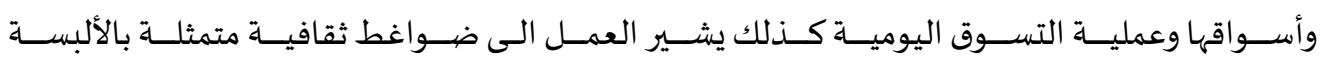

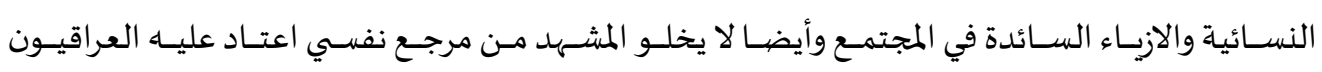

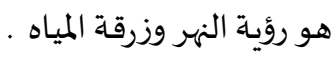
النتائج 1-تفاعل الفنان كان واضحا مع البيئة الطبيعية والبشرية فأصبحت هنالك مشاركة ملموسـة لها في الإنتاج. كما في العينة (2، 2، ماعنان

2-عملت المرجعيات الضاغطة (الثقافي والاجتماعي والديني ) على بلورة هوية الفنان. كما في عينة(2، ، 3 )

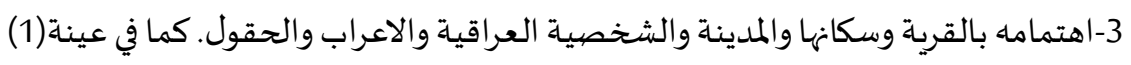

4-جسـ الكثير من المشكلات الاجتماعية خاصة المتعلقة بالحياة اليومية في اعماله. كما في عينة(1) 5- تجسيد الرموز الدينية عن طريق العلاقة بما تمثله من موضيوع جمالي يرتبط بمرجعها .كما في عينة(2)

1- المرجع الديني كان له الأثر الواضح في حياة كل فنان مما اثر في عملية الإنتاج والأبداع الفني 2-عكست طبيعة تفاعل الانسـان ببيئته بكل عواملها الى نشوء اسلوب مميز للفنان يؤكد فياه على هويته الفنية. 3-اظهار التأثير النفسي والسيكولوجي في العمل الفني عن طريق الأسلوب الذي تبناه الفنان. 


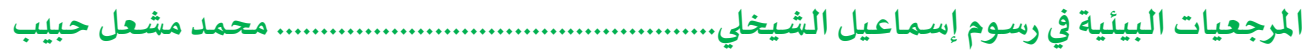

ISSN(Online) 2523-2029, ISSN(Print) 1819-5229 2019 مجلة الأكاديمي-العدد 94-السـنة
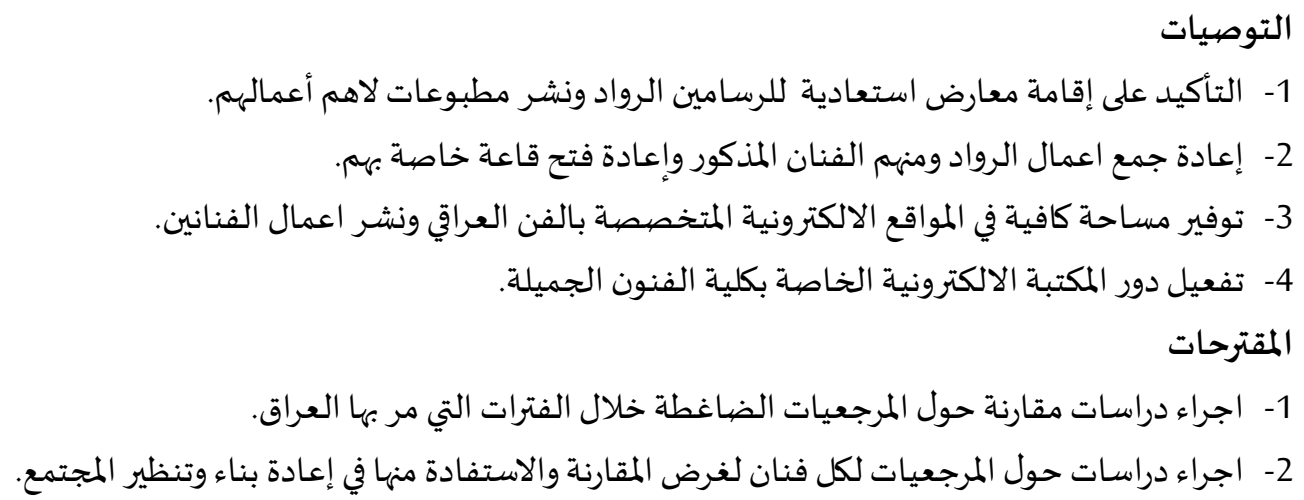

\section{References:}

The Holy Quran

1 - Ahmed Rashid Abdullah, Environment in the drawings of Ismail Sheikhli, University of Technology, Department of sports activity and artistic activity, Journal of the Professor, Volume I, No. 206.

2 - Ahmed: Mahoud, Ismail Sheikhli, Department of Fine Arts, Ministry of Culture and Information, Baghdad 1982.

3 - Ibn Manzour: Lanson Al Arab, C8, Dar Sader, Beirut,

4 - Plasim Mohammed: isolation of art in Iraqi culture, Association of Iraqi plastic artists, I 1, Baghdad.

5 - Hassan Hadi Hassan: social references of Baghdad School of Islamic Photography Morphological study, doctoral thesis, Faculty of Fine Arts, Baghdad, 2017

6 - Haider Kazem Sayed, references to abstraction in Islamic art, academic magazine number 90, 2018.

7- Saadi: Ibtisam Naji Kazem Al-Abidi: Rana Miri Mezal, The Environment in Contemporary Iraqi Ceramics, Babel University Journal of Humanities, Volume 23, No. 3

8- Al-Obaidi: Muhammad The impact of social environment and inheritance

9. Al-Dulaimi, Munther Fadhil Hassan, Nihilism in Post-Modern Drawings, 1st edition, Dar Safaa for Printing and Publishing 2012

10-Al-Alawi: Hossam Abdul Rahim, The Environment and its Impact on Art and Society, Al-Nour Foundation for Culture and Information, Readings 2359, 2014

11 - Muttalibi: Omar Majbel, the aesthetic leader in modern painting, unpublished doctoral thesis, Faculty of Fine Arts, Baghdad, 2008. 


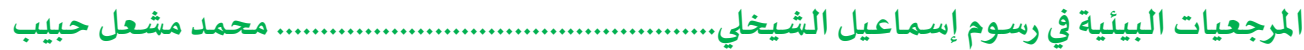

ISSN(Online) 2523-2029, ISSN(Print) 1819-5229 مجلة الأكاديمي-العدد 94-السنة 2019

12- Sahar Abdul Kadhim Ghanem, Stylistic Characteristics in Iraqi Painting (Ismail Al-Shaikhli Model), Mustansiriya University, Directorate of Artistic Activities.

13 - Suhad Hassan Mana Al - Aaydi: Social references in the works of Iraqi artists Analytical study, Master Thesis, Faculty of Fine Arts - University of Baghdad, 2016.

14-sahib: Zuhair, Iraqi plastic arts pre-writing era, issued by Iraqi Fine Artists Association, Dubai Press, Baghdad, 2007.

15 - Issa Salman, Yahya bin Mahmoud Al - Wasiti, painter, calligrapher, and the decorated, Baghdad, 1972.

16 - Alwan: Hassan Abdul, popular folktales in the drawings of Hassan Abdul Alwan, Master, Babil University, Faculty of Fine Arts, 2011.

17-Finkelstein: Sidney realism in art, translated by Mujahid Abdel Moneim Mujahid, review d, Yehia Howeidi, Cairo 1971.

18- Kamel, Adel: Modernity in Iraqi Plastic Art, Public Cultural House, Baghdad.

19- Kamel: Adel, Fine Art in Iraq, Pioneer Stage, Baghdad, Freedom House for Printing and Publishing, 1986.

20- Mohieddin Hani, Environment in the Art of Mesopotamia, unpublished doctoral dissertation, Faculty of Fine Arts, Baghdad, 1999.

21- Nada Ayed Yousef: Reference of Form in Postmodern Art, Unpublished Master Thesis, Faculty of Fine Arts, 2008.

22.waead Adnan Mahmoud's Promise: The Magic of the Marshlands, An Artful Reading of Iraqi Plastic Art, Publisher, Thamer Al-Amami Foundation, Baghdad, 2017. 


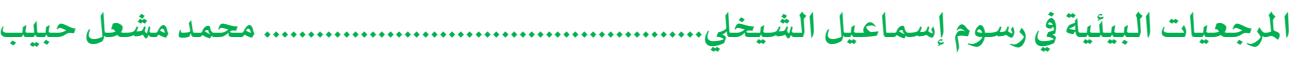

ISSN(Online) 2523-2029, ISSN(Print) 1819-5229 2019 مجلة الأكاديمي-العدد 94-السـنة

DOI: https://doi.org/10.35560/jcofarts94/203-220

\title{
Environmental References in the Drawings of Ismael Al-
} Shaikhli

\author{
Muhammad Meshaal Habib ${ }^{1}$
}

Al-academy Journal ............................... Issue 94 - year 2019

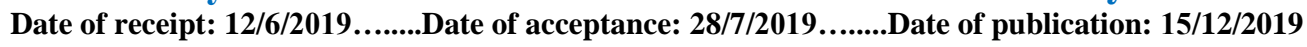

(c) (†) This work is licensed under a Creative Commons Attribution 4.0 International License

\begin{abstract}
The environmental references represented by the intellectual, social, economic, political and religious pressures are considered fundamental factors for the artistic achievement whose importance comes from their multiplicity and branching into natural and psychological pressures that affect the multiplicity, diversity and variability of the artistic and performative methods. Thus they determine the artist's orientations and the creative artistic visions are summoned through symbols and semantic signs of the visual surface, because the societal thought in art in general and the fine art in specific occupies an influential position that led to the formation of new data borrowed by the artist in modern artistic forms.
\end{abstract}

This research is concerned with studying the environmental references in the drawings of Ismael AlShaikhli, because the intellectual reservoir in the mind of the Iraqi artist in general is manifested in a mental image represented by the social, intellectual, psychological and historical factors and crystallizes his production which also determines his cultural identity which stems from the depth of this reality. Thus the subject of the diversity of the intellectual and social references that are influential in the nature of the artistic achievements presented, in terms of form and content, needs to be studied. The subject of the research entitled (the environmental references in the drawings of Ismael Al-Shaikhli) stems from this idea.

${ }^{1}$ College of Fine Arts. University of Baghdad. mohammadmishaal@yahoo.com 